\title{
Hemodynamic effects of S-nitrosocysteine, an intravenous regional vasodilator
}

David C. Stuesse, MDa

George D. Giraud, MD, $\mathrm{PhD}^{\mathrm{b}}$

Angelo A. Vlessis, MD, $\mathrm{PhD}^{\mathrm{a}, \mathrm{b}, \mathrm{c}}$

Albert Starr, MD ${ }^{\mathrm{d}}$

Donald D. Trunkey, MDa
From the Departments of Surgery and Physiology and Pharmacology, ${ }^{\mathrm{b}}$ Oregon Health Sciences University, Portland; Heart Institute of the Cascades, ${ }^{c}$ St Charles Medical Center, Bend; and Academic Center for Cardiac Surgery, ${ }^{d}$ Providence Health System, Portland, Ore.

Read at the Twenty-sixth Annual Meeting of The Western Thoracic Surgical Association, The Big Island, Hawaii, June 21-24, 2000.

Received for publication July 5, 2000; revisions requested Oct 30, 2000; revisions received Feb 2, 2001; accepted for publication March 8, 2001.

Address for reprints: David C. Stuesse, MD, 2805 SE, 43rd Ave, Portland, OR 97206 (E-mail: stuessed@ohsu.edu).

J Thorac Cardiovasc Surg 2001;122:371-7

Copyright (C) 2001 by The American Association for Thoracic Surgery

$0022-5223 / 2001 \$ 35.00+0 \quad \mathbf{1 2 / 6 / 1 1 5 6 9 9}$

doi:10.1067/mtc.2001.115699
Background: S-nitrosocysteine is a carrier form of nitric oxide that can be delivered intravenously. S-nitrosocysteine is rapidly metabolized by plasma (half-life $=2-3$ seconds), forming nitric oxide and cysteine. With its short half-life and potent vasodilatory properties, S-nitrosocysteine may be useful as a pulmonary vasodilating agent in cases of postoperative and chronic pulmonary hypertension.

Objective: Our objective was to determine the hemodynamic properties of Snitrosocysteine on the pulmonary and systemic circulations to assess its potential utility as a pulmonary vasodilatory agent.

Methods: Eleven adult swine were anesthetized. Thermodilution (Swan-Ganz; Baxter International, Inc, Deerfield, Ill) and arterial catheters were inserted. Flow probes were placed around the coronary, renal, superior mesenteric, and iliac arteries. Incremental infusion doses of S-nitrosocysteine $\left(5-80 \mathrm{nmol} \cdot \mathrm{kg}^{-1} \cdot \mathrm{min}^{-1}\right)$ were delivered into the right atrium. Cardiac output, right and left heart pressures, heart rate, $\mathrm{PaO}_{2}$, and iliac, renal, coronary, and mesenteric blood flow rates were recorded at baseline and at each infusion dose of S-nitrosocysteine.

Results: Low-dose S-nitrosocysteine infusion decreased mean pulmonary artery pressure $(15 \%, P=.013)$ without a significant reduction in mean systemic artery pressure. Higher dose infusions produced further dose-dependent declines in pulmonary vascular resistance and measurable reductions in systemic vascular resistance $(P=.01)$. At an S-nitrosocysteine dosage of $40 \mathrm{nmol} \cdot \mathrm{kg}^{-1} \cdot \mathrm{min}^{-1}$, there was a significant reduction in renal $(P<.001)$ and mesenteric $(P=.003)$ blood flow but no change in iliac $(P>.2)$ or coronary $(P>.2)$ blood flow. Cardiac output remained constant up to infusion rates of $40 \mathrm{nmol} \cdot \mathrm{kg}^{-1} \cdot \min ^{-1}(P>.2)$. Doses higher than $5 \mathrm{nmol} \cdot \mathrm{kg}^{-1} \cdot \mathrm{min}^{-1}$ resulted in a substantial dose-dependent reduction in $\mathrm{PaO}_{2}$ $(P<.001)$, suggesting dilation of atelectatic areas of the lung.

Conclusion: S-nitrosocysteine is a potent vasodilatory agent capable of overcoming the hypoxic vasoconstrictive response of the lung. Our results suggest it may prove useful as a pulmonary vasodilatory agent at low doses. Higher dose infusions reduce mean systemic pressure and lead to compensatory reductions in renal and mesenteric blood flow without a decrease in cardiac output.

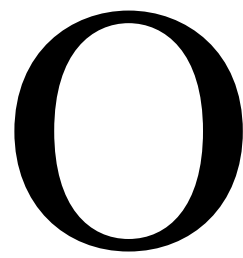

ftentimes in clinical practice, therapeutic measures are needed to lower pulmonary vascular resistance. Unfortunately, many of the agents used to lower pulmonary vascular resistance also exert additional undesirable effects on the rest of the cardiovascular system. Recently, inhaled nitric oxide has enjoyed some clinical success as a selective pulmonary vasodilating agent. The toxic effects 
of inhaled nitric oxide, as well as the expense of its administration, limit its widespread clinical utility. ${ }^{1}$

Nitric oxide is a naturally occurring vasoactive molecule produced from L-arginine by endothelial cells. Nitric oxide regulates vascular tone; free nitric oxide acts through a cyclic guanosine monophosphate-dependent pathway to produce arterial vasodilation. Nitric oxide is a free radical and, as such, has a short half-life ( $<1$ second) in plasma. ${ }^{2}$ Interestingly, nitric oxide also reacts with elements in the blood, forming more stable complexes that retain vasodilatory properties. One such class of compounds, S-nitrosothiols, can be formed under physiologic conditions from nitric oxide and the thiol groups of proteins and sulfhydryl amino acids. S-nitrosothiols are nitric oxide donors that have been identified in the human circulation and are believed to be the primary redox form of nitric oxide. ${ }^{3}$ The half-life of the various S-nitrosothiols is longer than that of nitric oxide itself. This potentially permits nitric oxide formed at one site to have a vasodilatory effect at another site in the circulation.

S-nitrosocysteine, the subject of our current study, is a lowmolecular-weight S-nitrosothiol with a short half-life in plasma (estimates range from 2-30 seconds). ${ }^{4,5} \mathrm{~S}$-nitrosocysteine is a potent vasodilator. In fact, Myers and colleagues ${ }^{6}$ originally postulated that S-nitrosocysteine may be an endothelium-derived relaxing factor. Several in vitro studies have demonstrated the vasodilatory properties of S-nitrosocysteine. We postulated that the longer half-life of S-nitrosocysteine, compared with that of nitric oxide, would allow its delivery into the right atrium, where its vasodilating effects would be exerted primarily in the pulmonary vasculature. The majority of the compound would be spontaneously degraded by the time it reached the left atrium, thereby having a lesser or minimal effect on the systemic circulation. In this study we characterize the in vivo cardiovascular effects of S-nitrosocysteine and assess its potential clinical utility as a selective pulmonary vasodilator by using a porcine model. Both the D- and L-isomers of S-nitrosocysteine were evaluated because of previous reports of a possible stereoselective effect. ${ }^{7}$

\section{Materials and Methods Chemical Preparation}

Base chemicals were purchased from Sigma-Aldrich Co (St Louis, Mo). S-D-nitrosocysteine and S-L-nitrosocysteine were synthesized by incubating equimolar concentrations of sodium nitrite, hydrochloric acid, and the corresponding thiol for 30 minutes at $4^{\circ} \mathrm{C}$ in the dark. The concentration of the stock solutions was confirmed spectrophotometrically by the Griess reaction. ${ }^{8}$ The nitrosothiol stock solution was serially diluted in normal saline solution to a final concentration of $3 \mathrm{mmol} / \mathrm{L}$. The final working solutions were kept on ice in the dark until the time of use.

\section{Animal Preparation and Experimentation}

All procedures, protocols, and anesthetics were approved and supervised by our institutional animal care committee and institu- tional research review board. Eleven adult swine (55-65 kg) were held from feed (but not water) for 1 day before experimentation. Anesthesia was induced with telazole, $10 \mathrm{mg} / \mathrm{kg}$ intramuscularly, followed by inhaled isoflurane and $2.5 \mathrm{mg}$ of intravenous fentanyl. After endotracheal intubation, anesthesia was sustained with $1.5 \%$ isoflurane and $1 \mathrm{mg} / \mathrm{h}$ intravenous fentanyl. Cutaneous oximetry and end-tidal carbon dioxide levels were monitored continuously, and the fraction of inspired oxygen $\left(\mathrm{FIO}_{2}\right)$ was maintained at $100 \%$ by means of mechanical ventilation. A warming blanket maintained normothermia.

Pulmonary artery, right atrial, and pulmonary capillary wedge pressures, as well as cardiac output, were measured by pulmonary artery catheters placed through the right external jugular vein. Systemic arterial pressure was measured with a common carotid artery catheter.

Electromagnetic flow probes (Carolina Medical, King, NC) were used to measure regional blood flows. After retroperitoneal exposure, flow probes were placed around the left renal, superior mesenteric, and left common iliac arteries. The heart was exposed by a median sternotomy approach. Coronary blood flow was measured by a flow probe on either the circumflex or left anterior descending coronary artery. After placement of the flow probes, all incisions were closed with skin clips.

The electromagnetic flow probe signals were analyzed by Statham-Gould SP2202 flowmeters (Gould Instrument Systems, Valley View, Ohio). Pulmonary artery, right atrial, and systemic arterial pressures were transduced continuously. Pulmonary capillary wedge pressure was measured periodically by the thermodilution occlusion technique. Hemodynamic data were continuously recorded with a Gould 2800S 8-channel chart recorder (Gould Instrument Systems, Valley View, Ohio). Cardiac output measurements using the thermodilution technique ${ }^{9}$ were obtained with an Edwards COM-1 cardiac output computer (Baxter Healthcare Corp, Edwards Division, Irvine, Calif). Arterial blood gas determinations were made with an Instrumentation Laboratory 1610 blood gas analyzer (Instrumentation Laboratories, Inc, Lexington, Mass) at each S-nitrosocysteine infusion dose.

After instrumentation, the animals were allowed to stabilize hemodynamically (approximately 30 minutes). Baseline recordings were then obtained. Next, the intravenous infusion of either Dor L-S-nitrosocysteine was initiated through the right atrial port of the pulmonary artery catheter. After the animal stabilized to a steady state (5 minutes) during infusion, recordings of arterial pressure, Swan-Ganz catheter readings, cardiac output, and local blood flow were recorded. Measurements were made at infusion rates of $0,5,10,20,40$, and $80 \mathrm{nmol} \cdot \mathrm{kg}^{-1} \cdot \mathrm{min}^{-1}$ of S-nitrosocysteine. The infusion was then terminated, and baseline recordings were obtained again. Blood samples were obtained at each infusion dose for blood gas analysis and serum nitrosothiol assays. After completion of the experiment, the animals were killed.

\section{Plasma Nitrosothiol Assay}

Blood was collected in 4-mL vacuum tubes containing $0.75 \mathrm{~mL}$ of $0.1 \mathrm{~mol} / \mathrm{L} \mathrm{KH}_{2} \mathrm{PO}_{4}(\mathrm{pH} 4.0)$ and $0.1 \mathrm{~mol} / \mathrm{L}$ ethylenediamine tetraacetic acid. Plasma was obtained by means of centrifugation. Plasma nitrosothiol concentration was determined by high-pressure liquid chromatography (Waters Co, Milford, Mo), as previously described by our laboratory. ${ }^{10}$ 


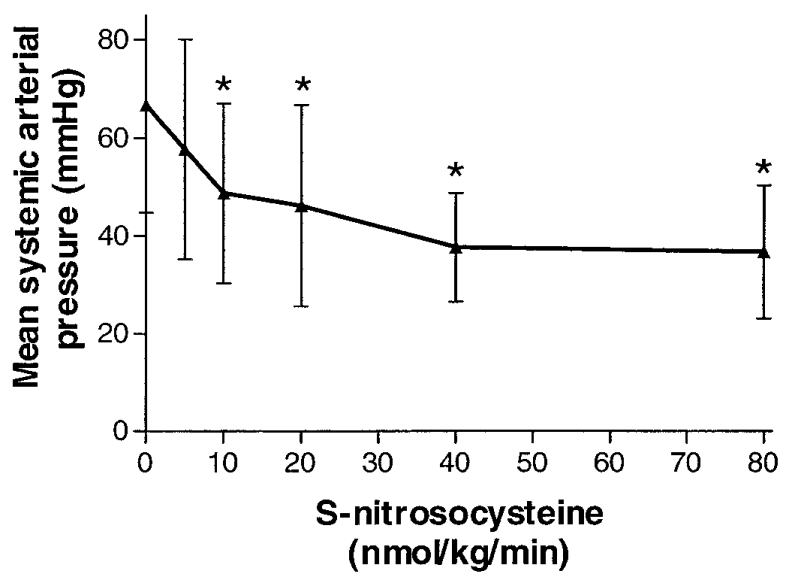

Figure 1. Effect of intravenous S-nitrosocysteine infusion on mean systemic arterial pressure. Values represent mean \pm SD. Asterisks represent a significant change in pressure compared with baseline values $(P<.05)$.

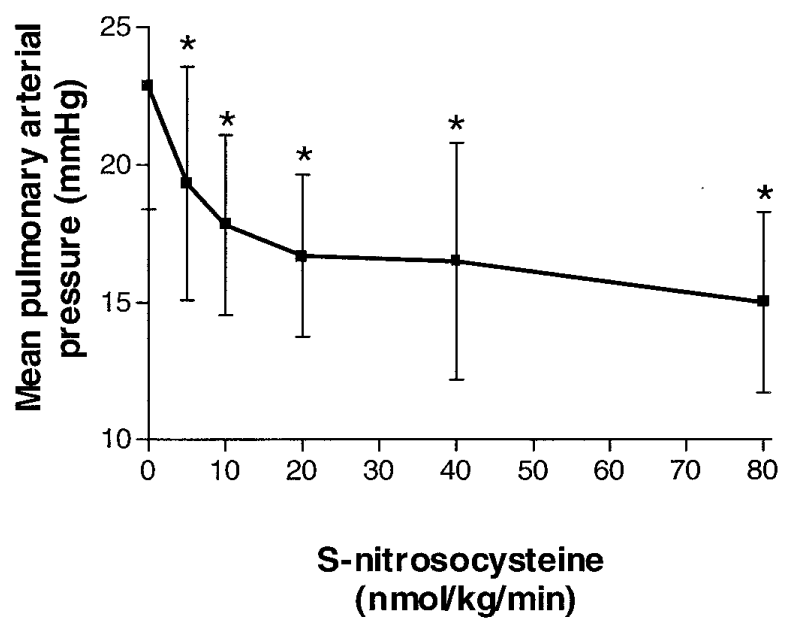

Figure 2. Effect of intravenous S-nitrosocysteine infusion on mean pulmonary arterial pressure. Each symbol represents mean \pm SD. Asterisks represent a significant change in pressure compared with baseline values $(P<.05)$.

TABLE 1. Hemodynamic measurements at varying levels of S-nitrosocysteine

\begin{tabular}{lccccccc}
\hline & $\begin{array}{c}\text { RAP } \\
(\mathbf{m m ~ H g})\end{array}$ & $\begin{array}{c}\text { PCWP } \\
(\mathbf{m m ~ H g})\end{array}$ & $\begin{array}{c}\text { HR } \\
(\text { beats/min) }\end{array}$ & $\begin{array}{c}\text { CO } \\
(\text { L/min) }\end{array}$ & $\begin{array}{c}\text { SV } \\
\text { (mL/beat) }\end{array}$ & $\begin{array}{c}\text { PVR } \\
\left(\text { dynes } \cdot \mathbf{s}^{-1} \cdot \mathbf{c m}^{-5}\right)\end{array}$ & $\begin{array}{c}\text { SVR } \\
\left(\text { dynes } \cdot \mathbf{s}^{-1} \cdot \mathbf{c m}^{-5}\right)\end{array}$ \\
\hline $0 \mathrm{nmol} \cdot \mathrm{kg}^{-1} \cdot \mathrm{min}^{-1}$ & $8 \pm 3.5$ & $11 \pm 4$ & $82 \pm 20$ & $4.5 \pm 1$ & $56 \pm 14$ & $221 \pm 76$ & $1082 \pm 382$ \\
$5 \mathrm{nmol} \cdot \mathrm{kg}^{-1} \cdot \mathrm{min}^{-1}$ & $8 \pm 3.2$ & $9 \pm 3.8$ & $82 \pm 20$ & $4 \pm 0.6$ & $51 \pm 15$ & $204 \pm 69$ & $1001 \pm 292$ \\
$10 \mathrm{nmol} \cdot \mathrm{kg}^{-1} \cdot \mathrm{min}^{-1}$ & $7 \pm 3.3$ & $9 \pm 3.8$ & $87 \pm 21$ & $4.2 \pm 1.1$ & $51 \pm 17$ & $172 \pm 49$ & $807 \pm 209$ \\
$20 \mathrm{nmol} \cdot \mathrm{kg}^{-1} \cdot \mathrm{min}^{-1}$ & $7 \pm 3.9$ & $9 \pm 3.4$ & $90 \pm 17$ & $4.2 \pm 1.2$ & $48 \pm 18$ & $160 \pm 47$ & $737 \pm 222$ \\
$40 \mathrm{nmol} \cdot \mathrm{kg}^{-1} \cdot \mathrm{min}^{-1}$ & $7 \pm 3$ & $9 \pm 3.3$ & $97 \pm 15$ & $4 \pm 1.1$ & $43 \pm 14$ & $172 \pm 98$ & $640 \pm 128$ \\
$80 \mathrm{nmol} \cdot \mathrm{kg}^{-1} \cdot \mathrm{min}^{-1}$ & $7 \pm 3$ & $9 \pm 3.5$ & $100 \pm 23$ & $3.7 \pm 1$ & $38 \pm 14$ & $147 \pm 49$ & $669 \pm 186$ \\
\hline
\end{tabular}

Values are given as means $\pm \mathrm{SD}$. RAP, Right atrial pressure; PCWP, pulmonary artery capillary wedge pressure; $H R$, heart rate; $C O$, cardiac output; $S V$, stroke volume; $P V R$, pulmonary vascular resistance; $S V R$, systemic vascular resistance.

\section{Statistical Analysis}

Statistical analysis was performed with SPSS software (SPSS, Inc, Chicago, Ill). Differences between infusion dose groups were determined by analysis of variance. Values are presented as means $\pm \mathrm{SD}$.

\section{Results}

Hemodynamic data recorded at each infusion rate of Snitrosocysteine are presented in Table 1. No significant differences whatsoever were detected between the D- and Lisomers of S-nitrosocysteine in all the measurements made in the study. Therefore, no stereospecific effect of the compound was identified. As a result, the data presented herein reflect the results obtained from both the D- and L-isomers of S-nitrosocysteine.

\section{Systemic and Pulmonary Arterial Pressure}

Low-dose S-nitrosocysteine $\left(5 \mathrm{nmol} \cdot \mathrm{kg}^{-1} \cdot \mathrm{min}^{-1}\right)$ had no significant effect on mean systemic arterial pressure
(Figure 1), whereas the mean pulmonary artery pressure decreased significantly from baseline $(23 \pm 4$ to $19 \pm 4$ $\mathrm{mm} \mathrm{Hg} ; P=.013$, Figure 2$)$. At a slightly higher dose (10 $\mathrm{nmol} \cdot \mathrm{kg}^{-1} \cdot \mathrm{min}^{-1}$ ), both systemic and pulmonary arterial pressures decreased. Systemic and pulmonary arterial pressures continued to decrease in a dose-dependent fashion at infusion rates above $10 \mathrm{nmol} \cdot \mathrm{kg}^{-1} \cdot \mathrm{min}^{-1}$ (Figures 1 and 2).

\section{Cardiac Performance}

No significant differences in cardiac output were observed throughout the dose range of S-nitrosocysteine studied (Table 1). Although calculated stroke volume decreased $(P=.007)$ at the higher infusion doses of S-nitrosocysteine $\left(40-80 \mathrm{nmol} \cdot \mathrm{kg}^{-1} \cdot \mathrm{min}^{-1}\right)$, cardiac output was maintained by a significant increase in heart rate $(P=.027)$. There was no significant change in either pulmonary capillary wedge pressure or right atrial pressure to account for the changes in stroke volume. 


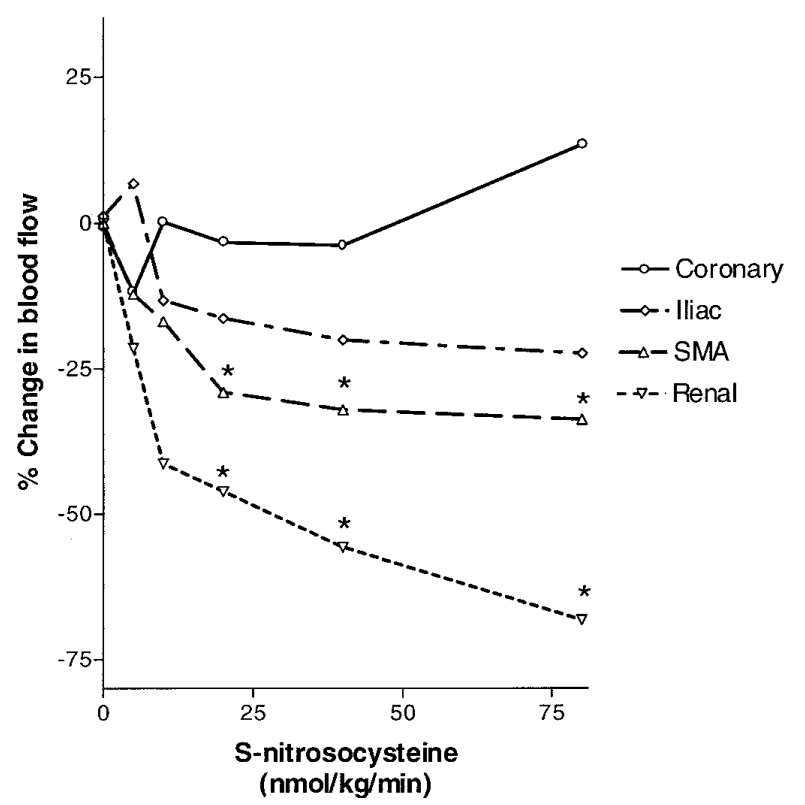

Figure 3. Effect of intravenous S-nitrosocysteine infusion on regional blood flows. Values are percentage changes from baseline for the superior mesenteric (SMA), renal, iliac, and coronary arteries. Each symbol represents the mean change in flow. Asterisks represent a significant change in flow compared with baseline values $(P<.05)$.

\section{Regional Blood Flow}

Renal and superior mesenteric artery blood flows declined with increasing infusion rates of S-nitrosocysteine, and the decrease of these blood flows reached statistical significance at infusion rates of $20 \mathrm{nmol} \cdot \mathrm{kg}^{-1} \cdot \mathrm{min}^{-1}$ and higher (Figure 3). Coronary and iliac artery flows were not statistically different at any infusion rate of S-nitrosocysteine studied. Superior mesenteric artery blood flow returned to baseline within 10 minutes of stopping the S-nitrosocysteine infusion. Although there was some recovery in renal arterial flow after stopping the $80 \mathrm{nmol} \cdot \mathrm{kg}^{-1} \cdot \mathrm{min}^{-1}$ infusion, renal arterial flow failed to return to preinfusion levels, even after 30 minutes.

\section{Arterial Blood Gas Analysis}

$\mathrm{PaO}_{2}$ decreased as the S-nitrosocysteine infusion dose increased, despite maintaining $\mathrm{FIO}_{2}$ at $100 \%$. The decrease in $\mathrm{PaO}_{2}$ was statistically significant at infusion doses of 10 $\mathrm{nmol} \cdot \mathrm{kg}^{-1} \cdot \mathrm{min}^{-1}$ and greater (Figure 4) and recovered to baseline within 5 minutes after discontinuing the S-nitrosocysteine infusion. $\mathrm{PaCO}_{2}$ and the $\mathrm{pH}$ remained constant at all doses of S-nitrosocysteine.

\section{Plasma S-nitrosothiol Concentration}

The relationship between infusion rates and measured plasma concentration of S-nitrosocysteine is shown in Figure 5. Statistically significant elevations in plasma levels were

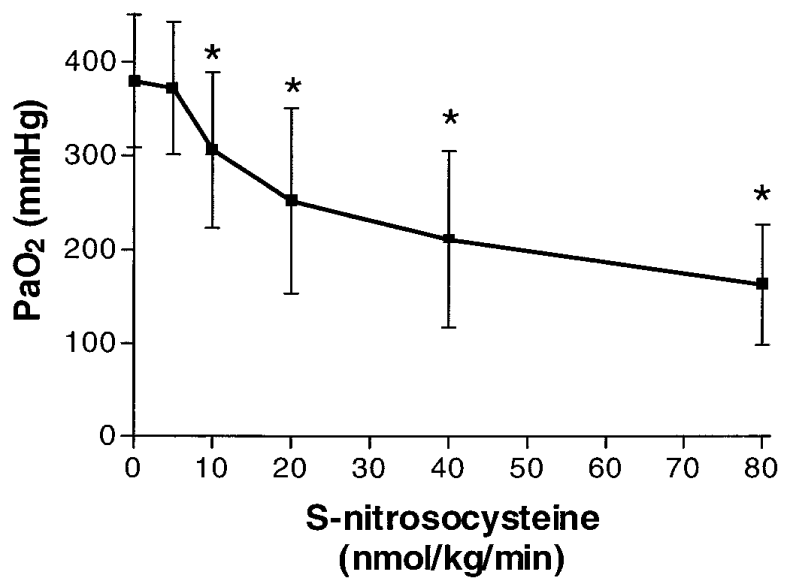

Figure 4. Effect of intravenous S-nitrosocysteine infusion on the systemic $\mathrm{PaO}_{2}$. Each symbol represents mean $\pm \mathrm{SD}$. Asterisks represent a significant change in partial pressure compared with baseline values $(P<.05)$.

obtained at doses of $10 \mathrm{nmol} \cdot \mathrm{kg}^{-1} \cdot \min ^{-1}$ and higher $(P<$ $.001)$. The relationship between infusion dose and measured arterial plasma concentration approximated linearity.

\section{Discussion}

S-nitrosocysteine is a potent vasodilator when administered intravenously. When used at low doses of $5 \mathrm{nmol} \cdot \mathrm{kg}^{-1}$. $\mathrm{min}^{-1}$ and delivered into the right atrium, its short half-life permits a reduction in mean pulmonary artery pressure without a significant effect on mean arterial pressure. At higher doses, however, a decrease in mean pressure in both the pulmonary and systemic circulation was observed. It is important to emphasize that these measurable changes in pulmonary vascular resistance were documented in animals with normal pulmonary circulation, and the magnitude of change may be much more dramatic in pathologic states in which pulmonary resistance is elevated. ${ }^{11}$

In clinical practice acute control of pulmonary hypertension may be necessary after heart or lung transplantation, in certain congenital heart conditions, and after adult valvular operations. Intravenous agents currently used to control pulmonary hypertension all have unwanted side effects on the cardiovascular system, particularly systemic vasodilation. The other well-established nitric oxide donors, sodium nitroprusside and nitroglycerin, when administered intravenously, are accompanied by significant systemic arterial and venous dilation. Our study demonstrates that S-nitrosocysteine may be useful as a pulmonary vasodilating agent with few systemic side effects when used in low doses. Recently, inhaled aerosolized sodium nitroprusside has been used in the treatment of pulmonary hypertension. ${ }^{12}$ It was effective as a selective pulmonary artery dilator at low doses but had systemic effects at high doses. At present, its role 
remains unclear. Newer ultrashort half-life nitric oxide donors (ie, PROLI/NO) are under evaluation. ${ }^{13}$

Another important distinction between the nitric oxide donors and many other vasodilatory agents is their mechanism of action. Nitric oxide donors act through the cyclic guanosine monophosphate system. This contrasts with other agents used as pulmonary artery vasodilators (ie, adenosine, prostaglandins, prostacyclins, dobutamine, amrinone, and isoproterenol), the actions of which are mediated though a cyclic adenosine monophosphate mechanism. ${ }^{14}$ The effects of low-dose S-nitrosocysteine may be even more valuable as a selective pulmonary vasodilator if used in conjunction with low doses of these other cyclic adenosine monophosphate-activating agents.

Inhaled nitric oxide gas has been used with some success to treat the hypoxia and pulmonary hypertension associated with adult respiratory distress syndrome and congenital heart disease. Delivered by means of inhalation, nitric oxide selectively vasodilates the ventilated portions of lung. In the setting of adult respiratory distress syndrome, it corrects ventilationperfusion mismatch and thereby improves oxygenation. ${ }^{15}$ However, inhaled nitric oxide use has many pitfalls, which include the development of pulmonary edema, rebound pulmonary hypertension, and vascular tolerance. ${ }^{16-18}$ Additionally, inhaled nitric oxide is a very reactive molecule capable of damaging tissues and thereby contributing to airway and parenchymal lung injury. In the presence of oxygen, nitric oxide is quickly converted to nitrogen dioxide, a toxic molecule. ${ }^{1}$ Nitrogen dioxide formation is accelerated at higher oxygen and nitric oxide concentrations. Other toxic effects may be mediated by peroxynitrite, a cytotoxic molecule formed from nitric oxide and superoxide. Interestingly, one study of acute lung injury showed that pretreatment with inhaled nitric oxide worsened lung injury, whereas pretreatment with intravenous sodium nitroprusside tended to mitigate the acute lung injury. ${ }^{19,20}$ Moreover, the use of inhaled nitric oxide is expensive, and its delivery is complex. An elaborate system for storage, blending, gas analysis, and scavenging is required. Most of these problems with nitric oxide inhalation therapy may be avoided by intravenous administration of less reactive and less toxic species, such as S-nitrosocysteine. ${ }^{18}$

Intravenously administered nitric oxide donors dilate the entire pulmonary vascular bed nonselectively. ${ }^{21}$ The normal hypoxic vasoconstrictive response in the lung is overcome, and atelectatic areas are perfused. This was dramatically demonstrated in this study by a dose-dependent decrease in $\mathrm{PaO}_{2}$ during S-nitrosocysteine infusion. Intravenous nitric oxide donors may be most useful in clinical situations when the major pathologic condition is increased right ventricular afterload and not hypoxia.

Clearly, S-nitrosocysteine has other effects in addition to vasodilation. In high doses systemic vasodilatation occurred simultaneously with splanchnic vasoconstriction. Cardiac

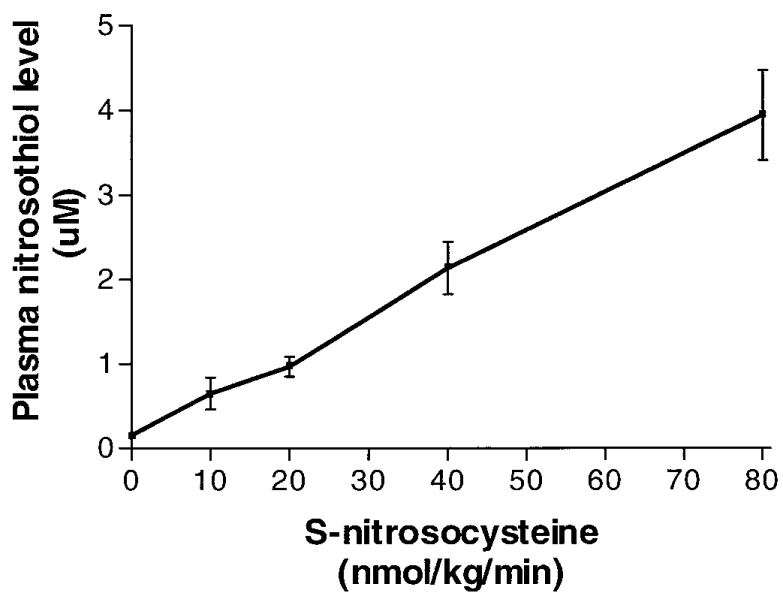

Figure 5. Relationship between S-nitrosocysteine intravenous infusion and nitrosothiol concentration in plasma from arterial blood. Values represent mean \pm SD.

output remained constant at all infusion doses despite a dose-dependent increase in heart rate, and thus stroke volume decreased as the S-nitrosocysteine infusion dose increased. No alterations in preload were observed. Therefore, at higher S-nitrosocysteine doses, diastolic ventricular function may decrease (ie, a decrease in lusitropy). With overlying changes in regional blood flow, it is difficult to postulate the exact mechanism, be it within the myocardium, systemic circulation, or both. Others have postulated a negative inotropic effect of nitric oxide and have even proposed that it may be the sought-after myocardial depression in sepsis. ${ }^{22}$ At the low doses used to modulate pulmonary vascular resistance, these myocardial or systemic circulatory effects are predictably minimal.

We compared D- versus L-S-nitrosocysteine because of previous reports of a possible stereoselective effect. In the mesenteric bed and hind limbs of rats, L-S-nitrosocysteine was a more potent vasodilator than D-S-nitrosocysteine, and the D-isomer was more effective than the L-isomer in inhibiting baroreceptor reflex-mediated tachycardia. ${ }^{7}$ A stereospecific effect would suggest the mechanism of Snitrosocysteine action takes place through a receptor-mediated process. Such stereoselective effects of the isomers were not seen in our in vivo model, and we conclude that the cardiovascular effects of S-nitrosocysteine are modulated through their degradation and the subsequent release of nitric oxide locally. A similar lack of stereospecificity has been reported in 2 recent studies in rats, in which the authors speculate that the effects of S-nitrosothiols on vascular relaxation are most likely caused by nonenzymatic nitric oxide release. ${ }^{23,24}$ However, other possible mechanisms for the vasoactive properties of S-nitrosocysteine do exist, including possible direct effects of the nitrosothiol, transnitrosation, or S-thiolation. $5,25,26$ 
Overall, the results presented herein show promise for Snitrosocysteine as a selective pulmonary vasodilating agent when used at low doses of 1 to $10 \mathrm{nmol} \cdot \mathrm{kg}^{-1} \cdot \mathrm{min}^{-1}$. Certainly, further studies in human subjects and in models of pulmonary hypertension are needed before the precise role of this S-nitrosothiol in clinical practice can be determined.

\section{References}

1. Fullerton DA, McIntyre RC Jr. Inhaled nitric oxide: therapeutic applications in cardiothoracic surgery. Ann Thorac Surg. 1996;61:1856-64.

2. Loscalzo J, Welch G. Nitric oxide and its role in the cardiovascular system. Prog Cardiovasc Dis. 1995;38:87-104.

3. Stamler JS, Jaraki O, Osbourne J, et al. Nitric oxide circulates in mammalian plasma primarily as an S-nitroso adduct of serum albumin. Proc Natl Acad Sci U S A. 1992;89:7674-7.

4. Hogg N. Biological chemistry and clinical potential of S-nitrosothiols. Free Radic Biol Med. 2000;408:1478-86.

5. Hayward CS, Kelly RP, Macdonald PS. Inhaled nitric oxide in cardiology practice. Cardiovasc Res. 1999;43:628-38.

6. Myers PR, Minor RL, Guerra R, et al. Vasorelaxant properties of endothelium derived relaxing factor more closely resemble S-nitrosocysteine than nitric oxide. Nature. 1990;345:161-3.

7. Davisson RL, Travis MD, Bates JN, Lewis SJ. Hemodynamic effects of L- and D-S-nitrosocysteine in the rat, stereoselective s-nitrosothiol recognition sites. Circ Res. 1996;79:256-62.

8. Saville B. A scheme for the colorimetric determinations of microgram amounts of thiols. Analyst. 1958;83:670-2.

9. Forrester JS, Ganz W, Diamond G, McHugh T, Chonette DW, Swan HJ. Thermodilution cardiac output determination with a single flowdirected catheter. Am Heart J. 1972;83:306-11.

10. Goldman RK, Vlessis AA, Trunkey DD. Nitrosothiol quantification in human plasma. Anal Biochem. 1998;259:98-103.

11. Megson IL, Grieg IR, Gray GA, et al. Prolonged effect of novel Snitrosated glycoamino acid in endothelium-denuded rat femoral arteries: potential as slow release nitric oxide donor drug. Br J Pharmacol. 1997; 122:1617-24.

12. Adrie C, Ichinose F, Holzmann A, Keefer L, Hurford WE, Zapol WM. Pulmonary vasodilation by nitric oxide gas and prodrug aerosols in acute pulmonary hypertension. J Appl Physiol. 1998;84:435-41.

13. Adrie C, Hirani WM, Holzmann A, Keefer L, Zapol WM, Hurford WE. Selective pulmonary vasodilation by intravenous infusion of an unltrashort half-life nucleophile/nitric oxide adduct. Anesthesiology. 1998;88:190-5.

14. Fullerton DA, Jaggers J, Piedalue F, Grover FL, McIntyre RC Jr. Effective control of refractory pulmonary hypertension after cardiac operations. J Thorac Cardiovasc Surg. 1997;113:363-70.

15. Walmrath D, Schermuly R, Pilch J, Grimminger F, Seeger W. Effects of inhaled versus intravenous vasodilators in experimental pulmonary hypertension. Eur Respir J. 1997;10:1084-92.

16. Brocci EA, Bacal F, Auler JOC Jr, Carmone MJE, Bellotti G, Peleggi F. Inhaled nitric oxide leading to pulmonary edema in stable severe heart failure. Am J Cardiol. 1994;74:70-2.

17. Lavoie A, Hall JB, Olson DM, Wylam ME. Life-threatening effects of discontinuing inhaled nitric oxide in severe respiratory failure. Am J Respir Crit Care Med. 1987;153:1985-7.

18. Miller MR, Roseberry MJ, Mazzeo FA, et al. Novel S-nitrosothiols do not engender vascular tolerance and remain effective in glyceryltrinitrate-tolerant rat femoral arteries. Eur J Pharmacol. 2000;408:335-43.

19. Rayhrer CS, Edminsten TD, Cephas GA, Tribble CG, Kron IL, Young JS. Nitric oxide potentiates acute lung injury in an isolated rabbit lung model. Ann Thorac Surg. 1998;65:935-8.

20. Young JS, Rayhrer CS, Edminsten TD, Cephas GA, Tribble CG, Kron IL. Sodium nitroprusside mitigates oleic acid-induced acute lung injury. Ann Thorac Surg. 2000;69:224-7.

21. Roos CM, Rich GF, Uncles DR, Daugherty MO, Frank DU. Sites of vasodilation by inhaled nitric oxide vs sodium nitroprusside in endothelin-constricted isolated rat lungs. J Appl Physiol. 1994;77:517.

22. Brady AJB, Poole-Wilson PA, Harding SE, Warren JB. Nitric oxide production within cardiac myocytes reduces their contractility in endotoxemia. Am J Physiol. 1992;263:H1963-6.

23. Cavero M, Hobbs A, Madge D, et al. Synthesis and biological evaluation of enantiopure thionitrites: the solid-phase synthesis and nitrosation of D-glutathione as a molecular probe. Bioorg Med Chem Lett. 2000;10:641-4.

24. Kashiba M, Kasahara E, Ehien KC, Inoue M. Fates and vascular action of S-nitrosoglutathione and related compounds in the circulation. Arch Biochem Biophys. 1999;363:213-8.

25. Travis MD, Hoque A, Bates JN, Lewis SJ. Blockade of voltage-sensitive $\mathrm{Ca}_{2}{ }^{++}$-channels markedly diminishes nitric oxide- but no L-Snitrosocysteine - or endothelium-dependent vasodilation in vivo. Eur J Pharmacol. 2000;408:289-98.

26. Jourd'heuil D, Hallen K, Feelisch M, Grisham MB. Dynamic state of S-nitrosothiols in human plasma and whole blood. Free Radic Biol Med. 2000;28:409-17.

\section{Discussion}

Dr Edward Verrier (Seattle, Wash). The authors have described hemodynamic effects of varying doses of S-nitrosocysteine in normal adult sheep. Nitrocysteine is an intravenous carrier form of nitric oxide, and at very low doses of approximately 5 $\mathrm{nmol} / \mathrm{kg}$, this compound appears to selectively reduce pulmonary vascular resistance and pulmonary artery pressures without systemic effects. At very slightly higher doses, however, from $10 \mathrm{nmol}$ all the way up to $80 \mathrm{nmol}, 2$ major effects are noted: a reduction in systemic vascular resistance with subsequent systemic redistribution of flow with reductions in renal and mesenteric blood flow and a significant reduction in arterial oxygenation at a constant $\mathrm{FIO}_{2}$ at all doses above $5 \mathrm{nmol}$. The presentation has been excellent, the article is well written, and the science is sound, although it does not necessarily recreate the usual clinical scenario of pulmonary hypertension.

I have one major methodologic concern to address to the authors and then some concluding concerns when comparing the intravenous form to the inhaled, more commonly used nitric oxide form. First, the methodologic concern. You note a concern with nitric oxide-related toxicity. The usual described toxicity of nitric oxide relates to the binding of nitric oxide to hemoglobin, displacing oxygen and forming methemoglobin. At relatively low doses, you note a reduction in arterial oxygenation, yet you did not measure methemoglobin, a relatively simple assay. How do you know that the reduction in $\mathrm{PaO}_{2}$ was not due to a similar methemoglobin toxicity and had nothing to do with your proposed mechanism of "selectively dilating atelectatic areas of lung?"

The corollary question relates to the fact that S-nitrosocysteine is an intravenous nitric oxide donor compound, which gets to the vascular smooth muscle through the bloodstream, in comparison with the inhaled form, which theoretically gets to the vascular smooth muscle before it gets into the bloodstream, therefore making the intravenous form potentially more toxic. What are your thoughts?

Dr Stuesse. It is true we did not measure the methemoglobin levels, and it is possible that they could contribute to the decrease in the $\mathrm{PaO}_{2}$. However, in previous studies of methemoglobinemia with nitric oxide donors, the level of methemoglobin was not very high and probably could not contribute to such a dramatic decline. 
Dr Verrier. The reversibility as soon as the drug is discontinued is striking, which to me makes the methemoglobinemia issue potentially real.

Dr Stuesse. I believe the short half-life of nitrosocysteine also can explain why when we turn the infusion off the animal would recover just as quickly. I think the major difference between intravenous nitrosocysteine and inhaled nitric oxide is that inhaled nitric oxide is delivered only to the ventilated portions of the lung. Therefore, in a situation of adult respiratory distress syndrome and poor oxygenation, inhaled nitric oxide is really the treatment of choice because it increases perfusion of ventilated areas of the lung. However, nitrosocysteine does the opposite. In the clinical situation of hypoxia, intravenous infusion of nitrosocysteine could worsen the condition by increasing the shunt fraction in the lung.

Dr Verrier. You note the toxicity and expense of inhaled nitric oxide; in reality, in the doses up to $40 \mathrm{ppm}$ of inhaled nitric oxide, there is no parenchymal damage from the formation of nitrogen dioxide, which you note in your article, and this has not been reported clinically to my knowledge. The expense issue in the year 2000 is due to the company with exclusive patent rights charging exorbitant fees and not because the aerosolized form of nitric oxide is either difficult or expensive to either make or store. In contrast, your compound does not look simple to make, as you described eloquently in your "Materials and Methods" section. It has a very short half-life, cannot be made up in advance, and cannot be stored; plus it appears that the intravenous form has a very narrow therapeutic window. At the University of Washington, we have used inhaled nitric oxide in over 150 patients with pulmonary hypertension over the past few years and have not found the delivery system difficult to use or the inhaled compound toxic at all. Would you please readdress the toxicity and expense issues in your closing comments?
Dr Stuesse. Actually the nitrosocysteine is quite easy to create. I would synthesize it the morning before the experiment. It takes approximately 15 or 20 minutes. At $4^{\circ} \mathrm{C}$, it is stable for several days. The materials used to create nitrosocysteine are quite inexpensive. I believe that there are still problems with inhaled nitric oxide. The availability, scavenging system, and delivery system are issues. It is complex and more expensive than intravenous nitrosocysteine.

In summary, I think nitrosocysteine is very easy to administer, has a low cost, and may be applicable in situations in which there is not systemic hypotension or hypoxia.

Dr David Fullerton (Chicago, Ill). For those in the audience who are unfamiliar with the work that you have done in the past, this is one of a series of studies that have been ongoing in your laboratory and have advanced things in a very nice direction.

I was impressed that the data you presented are really quite similar to what one would expect if one infused other carriers of nitric oxide, such as nitroglycerin or nitroprusside. Those, of course, are clinically available and used on a daily basis. Have you done any comparison studies, and might this offer an advantage over either of those 2 molecules?

Dr Stuesse. The theoretic advantages of nitrosocysteine over those readily available molecules are the following. Its half-life is considerably shorter. The half-life of nitroprusside in plasma is 2 to 3 minutes, whereas that of nitrosocysteine is 2 to 3 seconds. As such, you are able to deliver more nitric oxide to the lung and less to the systemic circulation than with nitrosocysteine. Nitrosocysteine is also approximately 10 -fold more potent than the other carriers. Finally, we did not find any significant effects on the venous circulation in contrast to other agents.

\section{Timely}

The Journal of Thoracic and Cardiovascular Surgery delivers the information you need now. Articles usually appear within four months of acceptance. 